\title{
SISTEM PENDUKUNG KEPUTUSAN PENEMPATAN KARYAWAN MENGGUNAKAN METODE PROFILE MATCHING
}

\author{
Rahmadini Darwas $^{1}$, Aris Subadi ${ }^{2}$ \\ 1,2DosenSistem Informasi STMIK Indonesia Padang \\ Jl. Khatib Sulaiman Dalam No. 1, Padang \\ Email: ${ }^{1}$ dini@stmikindonesia.ac.id
}

Submitted: 16-03-2017, Reviewed: 17 -03- 2017, Accepted 18-03-2017

http://dx.doi.org/10.22202/jei.2017.v3i2.1670

\begin{abstract}
Abstrak
Penempatan karyawan dengan dukungan sistem pendukung keputusan merupakan salah satu implementasi perkembangan teknologi informasi.Agar karyawan dapat melaksanakan tugas dan peran pada jabatan yang didudukinya secara tepat dan produktif, karyawan harus mempunyai bebeapa kriteria seperti pengetahuan, keterampilan, sikap, dan perilaku yang baik.Penempatan karyawan ini ditujukan guna menjaga keseimbangan antara tenaga kerja dengan komposisi pekerjaan atau jabatan. Metode yang digunakan pada penelitian ini adalah metode profile matching, yaitu membandingkan antara nilai target yang harus dicapai karyawan dengan nilai yang dimiliki berdasarkan potensinya sehingga dihasilkan selisih antara perbandingan kedua nilai tersebut (gap). Penelitian ini menghasilkan urutan rangking dari karyawan yang memiliki kinerja baik dan telah diseleksi, serta output dari sistem pendukung keputusan tersebut dapat membantu pengambil keputusan dalam memilih alternatif penempatan karyawan.Software ini dibuat dengan menggunakan bahasa pemrograman PHP dan database menggunakan MySQL.
\end{abstract}

Kata Kunci : Sistem pendukung keputusan, profile matching,penempatan karyawan

\begin{abstract}
Placement of employees with the support decision support system is one implementation of the development of information technology. So that employees can carry out tasks and roles in the Office serving precisely and productive, employees need to have several criteria such as knowledge, skills, attitudes, and behaviors. The placement of employees is intended to keep the balance between workforce composition of the job or position. The methods used in this research is a method of profile matching, i.e. Comparing the interrelations between the value of the target to be achieved by the value of employee-owned on the basis of its potential so that the resulting difference between the comparison of both those values (gap). This research resulted in the order of rank of employees who have good performance and has been selected, as well as
\end{abstract}


the output of a decision support system that can help the decision maker in choosing an alternative placement of employees. This software is created by using the PHP programming language and uses the MySQL database.

Keywords: decision support system,profile matching, Placement of employees

\section{PENDAhuluan}

Penempatan tugas sangat perlu dilakukan sebagai perencanaan karir pegawai dan juga untuk meremajakan suatu posisi jabatan.Karyawan yang ditempatkan sesuai dengan pengetahuan, keterampilan dan kemampuannya cenderung memiliki motivasi yang tinggi, maka kinerja yang dihasilkan juga akan meningkat. (Nanda \& Yani 2016).Ditentukannya suatu kriteria-kriteria dalam penempatan tugas karyawan tidak terlepas dari tujuan agar karyawan yang akan dipindahkan memenuhi kriteria yang telah ditetapkan. Dalam proses penempatan tugas dan perencanaan karir di dalam suatu perusahaan hanya berdasarkan dari beberapa aspek saja yaitu tingkat pendidikan, lamanya waktu bekerja dan menggunakan metode konvesional ,yaitu dengan melalui tes administrasi tes psikologi dan wawancara. Namun beberapa aspek tersebut tidaklah cukup untuk menopang berhasilnya suatu pengambilan keputusan yang tepat. Dengan sistem pengambilan keputusan (SPK) yang baik maka akan menghasilkan suatu pengambilan keputusan yang baik pula.SPK tidak untuk menggantikan fungsi pengambil keputusan dalam membuat keputusan, melainkan hanyalah sebagai alat bantu pengambil keputusan dalam melaksanakan tugasnya(Putri \& Saleh 2016)

Agar pegawai dapat melaksanakan tugas dan peran pada jabatan di tempat yang didudukinnya secara tepat dan produktif, karyawan harus memiliki beberapa kriteria seperti pengetahuan, ketrampilan, sikap dan perilaku yang baik. Sistem pengambilan keputusan ini dibangun untuk membantu perusahaan dalam proses penempatan karyawan yang memiliki kinerja baik. Karyawan yang berkinerja baik akan dipindah tugaskan guna menjaga keseimbangan antara tenaga kerja dengan komposisi pekerjaan atau jabatan.

\section{TINJAUAN PUSTAKA}

\subsection{Tinjauan Mutakhir}

Penelitian tentang sistem pendukung keputusan menggunakan metode profile matching telah beberapa kali dilakukan sebelumnya

Menurut (Setiawati et al. 2016)Tes Dominant - Influence - SteadyCompliance (DISC) merupakan salah satu alat tes psikologi yang dijadikan alat oleh beberapa perusahaan untuk mengetahui tingkat kepribadian karyawannya. Tes ini berguna agar perusahaan mengetahui kepribadian 
karyawannya dari aspek current style, pressure style dan self style sehingga tes ini dapat membantu proses penempatan karyawan sesuai dengan kepribadiaannya.Hasil dari tes DISC ini dijadikan sebagai kriteria pendukung yang dihitung menggunakan metode Profile Matching dan menghasilkan perangkingan. Hasil dari penelitian ini berupa rekomendasi karyawan yang dapat menempati suatu jabatan sesuai dengan kepribadiannya dengan keakurasian data yang di uji sebesar $85,8 \%$.

Penelitian lainnya dilakukan oleh (Ariantono et al. 2015), dalam penelitiannya yaitu Sistem Pendukung Keputusan (SPK) menggunakan metode profile matching dapat menganalisis beberapa pegawai Aparatur Sipil Negara (ASN) yang sesuai dengan profil jabatan yang ada, agar SDM dapat ditempatkan pada posisi jabatan yang sesuai dengan karakteristik yang diperlukan. Proses Pengangkatan jabatan selama ini dilakukan secara manual dan belum adanya database untuk penyimpanan profil jabatan yang akan di tempati dan profil pegawai yang akan mengisi jabatan tersebut. Dengan adanyan sistem pendukung keputusan tersebut dapat membantu memberikan rekomendasi pegawai ASN dalam kenaikan pangkat jabatan pada instansi pemerintahan terkait dengan metode profile matching, dimana sistem mencocokan profil jabatan yang akan ditempati dengan profil pegawai ASN yang akan menempati posisi tersebut.

Dari beberapa penelitian yang pernah dilakukan tersebut, maka akan dibuat suatu aplikasi sistem pendukung keputusan penempatan karyawan menggunakan metode profile matching dimana penentuan rangking berdasarkan pada aspek kecerdasan, sikap kerja dan perilaku.

\subsection{Sistem Pendukung Keputusan}

Sistem pendukung keputusan menurut Keen dan Scoot Morton dalam Turban $\mathrm{E}$ adalah sebagai berikut, sistem pendukung keputusan merupakan pasangan intelektual dari sumber daya manusia dengan kemampuan komputer untuk memperbaiki keputusan, yaitu sistem pendukung keputusan berbasis komputer bagi pembuat keputusan manajemen yang menghadapi masalah semi terstruktur. Gory dan Scoot-Marton, mendefinisikan sistem pendukung keputusan sebagai kumpulan prosedur basis model untuk memproses data dan keputusan guna membantu manajer dalam membuat keputusan. Supaya sukses sistem harus sederhana, sehat, mudah dikendalikan, adaptif, lengkap dalam persoalan penting dan mudah untuk 
Penelitian Bidang Komputer Sains dan Pendidikan Informatika V3.i2(136-146)

didokumentasikan(Ananta \& Winiarti 2013)

\subsection{Profile Matching}

Proses profile matching secara garis besar merupakan proses membandingkanantara kompetensi seorang pegawai ke dalam kompetensi jabatan sehingga dapat diketahui perbedaan kompetensinya (disebut juga gap). Semakin kecil gap yang dihasilkan maka bobot nilainya semakin besar, yang berarti memiliki peluang lebih besar bagi seorang calon pegawai untuk bisa diterima(Ananta \& Winiarti 2013). Sistem kompetensi akan mendeskripsikan prestasi dan potensi sumber daya manusia sesuai dengan unit kerjanya. Pencapaian prestasi karyawan dan potensinya dapat terlihat apakah kompetensinya tersebut telah sesuai dengan tugas pekerjaan yang dimilikinya(Kasus et al. 2013).

Dalam penentuan peringkat (ranking) kandidat terdapat aspek yang menentukan, adalah sebagai berikut : (Handojo et al. 2003)

- Aspek Kapasitas Intelektual / Kecerdasan

- Aspek Sikap Kerja

- Aspek Perilaku

Tahapan dan perumusan perhitungan dengan metode profile matching adalah sebagai berikut.
Pada tahap ini, akan ditentukan bobot nilai masing-masing aspek dengan menggunakan bobot nilai yang telah ditentukan bagi masing-masing aspek itu sendiri. Adapun inputan dari proses pembobotan ini adalah selisih dari profil jabatan dengan profil karyawan yang diinginkan(gap). Dalam penentuan peringkat pada aspek kapasitas intelektual, sikap kerja dan perilaku untuk jabatan yang sama pada setiap gap, Gap merupakan suatu alat yang digunakan untuk mengevaluasi kinerja. Metode ini merupakan salah satu metode yang umum digunakan dalam pengelolaan manajemen suatu lembaga. Secara harfiah kata "gap" mengindikasikan adanya suatu perbedaan (disparity) antara satu hal dengan hal lainnya(Nuraini et al. 2011).diberikan bobot nilai sesuai dengan tabel 1 berikut

Tabel 1: Bobot Nilai Gap

\begin{tabular}{|c|c|c|c|}
\hline No & Selisih Gap & Bobot Nilai & Keterangan \\
\hline 1 & 0 & 5 & $\begin{array}{c}\text { Kompetensi sesuai dengan yang } \\
\text { ditutuhlan }\end{array}$ \\
\hline 2 & 1 & 4.5 & $\begin{array}{c}\text { Kopetensi individu keletihan } 1 \text { tingkat } \\
\text { level }\end{array}$ \\
\hline 3 & -1 & 4 & \begin{tabular}{|c} 
Kopetensi incividu kurang I tingkat / \\
level
\end{tabular} \\
\hline 4 & $?$ & 35 & $\begin{array}{c}\text { Kopetensi individu keletihan } 2 \text { tingkat } \\
\text { Ilevel } \\
\end{array}$ \\
\hline 5 & -2 & 3 & $\begin{array}{c}\text { Kopetensi individu kurang } 2 \text { tinghat / } \\
\text { level }\end{array}$ \\
\hline 5 & 3 & 2.5 & $\begin{array}{c}\text { Kopetensi individu keletihan } 3 \text { tingkat } \\
\text { level } \\
\end{array}$ \\
\hline 7 & -3 & 2 & \begin{tabular}{|c} 
Kopetensi in dividu kurang 3 tingkat / \\
level \\
\end{tabular} \\
\hline 8 & 4 & 1.5 & $\begin{array}{c}\text { Kopctcnsi individu kclctihan } 4 \text { tingkat } \\
\text { ilevel }\end{array}$ \\
\hline 9 & -4 & 1 & $\begin{array}{c}\text { Kopetensi individu kurang } 4 \text { tingkat } \\
\text { level }\end{array}$ \\
\hline
\end{tabular}

Sumber : Konsep dan Aplikasi a. Pembobotan 
Penelitian Bidang Komputer Sains dan Pendidikan Informatika V3.i2(136-146)

Sistem Pendukung Keputusan

(Kusrini 2007)

b. Perhitungan dan Pengelompokkan

Core Factor dan Secondary

Factor

Setelah menentukan bobot nilai gap untuk ketiga aspek yang dibutuhkan, kemudian tiap aspek dikelompokkan lagi menjadi 2 kelompok yaitu core factor dan secondary factor

- Core Factor

merupakan aspek (kompetensi) yang paling menonjol/paling dibutuhkan oleh suatu jabatan yang diperkirakan dapat menghasilkan kinerja optimal. Untuk Menghitung core factor digunakan rumus :

$\mathrm{NCF}=\frac{\Sigma N C}{\Sigma I C}$

Keterangan :

$\mathrm{NCF}=$ Nilai rata-rata core factor

$\mathrm{NC}=$ Jumlah total nilai core factor

IC = Jumlah item core factor

- Secondary Factor

Secondary factor adalah item-item selain aspek yang ada pada core factor. Untuk menghitung secondary factor digunakan rumus :

$\mathrm{NSF}=\frac{\Sigma N S}{\Sigma I S}$

Keterangan :

NSF $=$ Nilai rata-rata secondary factor

$\mathrm{NS}=$ Jumlah total nilai secondary factor

IS = Jumlah item secondary factor

c. Perhitungan Nilai Total Tiap Aspek

Dari perhitungan core factor dan secondary factor dari tiap-tiap aspek, kemudian dihitung nilai total dari tiap-tiap aspek yang diperkirakan berpengaruh pada kinerja tiap-tiap profile. Untuk menghitung nila total dari masing- masing aspek, digunakan rumus :

$$
\mathrm{N}=40 \% \mathrm{NC}+60 \% \mathrm{NSc}
$$

Keterangan :

$\mathrm{N}=$ Nilai Total Tiap Aspek

$\mathrm{NC}=$ Nilai Core Factor

NSc = Nilai Secondary Factor

d. Perhitungan Ranking

Hasil akhir dari proses profile matching adalah rangking dari kandidat yang diajukan untuk mengisi suatu jabatan/posisi tertentu. Penentuan mengacu rangking pada hasil perhitungan yang ditujukan pada rumus di bawah ini :

Rangking $=20 \% \mathrm{NKI}+30 \% \mathrm{NSK}$

$+50 \% \mathrm{NP}$

Keterangan :

$\mathrm{N}=$ Nilai Kapasitas Intelektual

$\mathrm{NCI}=$ Nilai Sikap Kerja

NSI $=$ Nilai Perilaku

\section{METODE PENELITIAN}

Subjek penelitian adalah sistem pendukung keputusan penempatan karyawan kenaikan jabatan 
Penelitian Bidang Komputer Sains dan Pendidikan Informatika V3.i2(136-146)

menggunakan bahasa pemograman PHP.Penelitian ini bersifat internal untuk membantu perusahaan. Metode yang digunakan adalah metode profile matching yaitu dengan membandingkan antara kompetensi seorang pegawai ke dalam kompetensi jabatan sehingga dapat diketahui perbedaan kompetensinya (disebut juga gap). Metode pengumpulan data yang dipakai yaitu metode Wawancara (interview), observasi, dan studi pustaka.Metode analisa yang digunakan adalah metode kuantitatif dan analisa sistem.Analisis sistem informasi difokuskan kepada masalah dan kebutuhan bisnis, tidak tergantung pada teknologi apapun yang akan atau dapat digunakaan untuk mengimplementasikan solusi masalah(Firdaus \& Bardadi 2010)

\section{HASIL DAN PEMBAHASAN}

Pada penelitian ini, penentuan kriteria yang akan digunakan ditentukan oleh Pimpinan (Decision Maker) yang disesuaikan dengan aturan-aturan yang ada pada objek penelitian.

a. Aspek Peniliaian

Menentukan aspek dan kriteria yang akan dinilai dalam proses penempatan karyawan. Masingmasing aspek memiliki total nilai persentase $100 \%$

Tabel 2: Aspek Penilaian Karyawan Pada PT Laju Perdana Indah

\begin{tabular}{|l|l|l|}
\hline Aspek & Persentase & Kriteria \\
\hline Kecerdasan & $30 \%$ & $\begin{array}{l}\text { - Sistematika Berpikir } \\
\text { - Logika Praktis } \\
\text { - Konsentrasi } \\
\text {-Antisipasi }\end{array}$ \\
\hline Sikap Kerja & $35 \%$ & $\begin{array}{l}\text {-Ketelitian dan tanggung } \\
\text { jawab } \\
\text {-kehati-hatian } \\
\text {-Vitalitas dan perencanaan - } \\
\text { Dorongan berprestasi }\end{array}$ \\
\hline Perilaku & $35 \%$ & $\begin{array}{l}\text { - kekuasaan } \\
\text {-Pengaruh } \\
\text {-Keteguhan hati } \\
\text {-Pemenuhan }\end{array}$ \\
\hline
\end{tabular}

b. Proses Penilaian Karyawan

Berdasarkan aspek penilaian

Tabel 3: Nilai Aspek Kecerdasan

Karyawan

\begin{tabular}{|ll|l|l|l|l|}
\hline No & Id karyawan & $\begin{array}{l}\text { Sistematika } \\
\text { bepikir }\end{array}$ & $\begin{array}{l}\text { Logika } \\
\text { praktis }\end{array}$ & Konsentrasi & antisipasi \\
\hline 1 & K001 & 3 & 4 & 3 & 2 \\
\hline 2 & K002 & 4 & 3 & 4 & 5 \\
\hline 3 & K003 & 2 & 4 & 4 & 3 \\
\hline
\end{tabular}

Tabel 4: Nilai Aspek Sikap Kerja Karyawan

\begin{tabular}{|c|c|c|c|c|c}
\hline Vo & Id Karvawan & $\begin{array}{c}\text { Ketelitian dan } \\
\text { Tanggmgjawab }\end{array}$ & $\begin{array}{c}\text { Kehati- } \\
\text { hatian }\end{array}$ & $\begin{array}{c}\text { Vitalitas } \\
\text { dan } \\
\text { Perancanaan }\end{array}$ & $\begin{array}{c}\text { Derongan } \\
\text { bemprestasi }\end{array}$ \\
\hline 1 & KC01 & 3 & 4 & 3 & 4 \\
\hline 2 & KC02 & 4 & 3 & 4 & 3 \\
\hline 3 & K003 & 2 & 5 & 3 & 4 \\
\hline
\end{tabular}

Tabel 5: Nilai Aspek Perilaku Karyawan

\begin{tabular}{|c|c|c|c|c|c|}
\hline No & Id_Karyawan & Kekusaan & Pengaruh & $\begin{array}{c}\text { Keteguhan } \\
\text { Hat: }\end{array}$ & Pemenuhan \\
\hline 1 & K001 & 4 & 3 & 3 & 4 \\
\hline 2 & K002 & 4 & 4 & 3 & 3 \\
\hline 3 & K003 & 4 & 3 & 4 & 5 \\
\hline
\end{tabular}

\section{c. Pemetaan Gap}

Tahap pemetaan gap adalah proses menghitung selisih nilai kriteria yang telah ditentukan pimpinan dengan nilai perolehan yang didapat oleh karyawan

Tabel 6: Pemetaan Gap 
Penelitian Bidang Komputer Sains dan Pendidikan Informatika V3.i2(136-146)

\begin{tabular}{|c|c|c|c|c|c|c|c|c|c|c|c|}
\hline \multirow{2}{*}{ No } & \multicolumn{4}{|c|}{ kaun } & \multicolumn{4}{|c|}{ KAUZ } & \multicolumn{3}{|c|}{ K103 } \\
\hline & Aakgayowan $\bar{k}$ & \begin{tabular}{l|l|}
$k 1$ & $k 2$ \\
\end{tabular} & \begin{tabular}{|l|l|}
2 & $\mathrm{~K} 3$ \\
\end{tabular} & & Sk1 & SK2 & & & \begin{tabular}{l|l}
$p_{1}$ & $\mathrm{p}$
\end{tabular} & P2 ${ }^{\text {r3 }}$ & \\
\hline 1 & K001 & \begin{tabular}{l|l}
3 & 4 \\
\end{tabular} & 3 & & 3 & 4 & ${ }^{3} 4$ & 4 & 4 & $3^{3} 3$ & \\
\hline 2 & K002 & \begin{tabular}{l|l}
4 & 3 \\
\end{tabular} & 4 & & 4 & 3 & & & 4 & $4=3$ & 3 \\
\hline 3 & кө0? & 24 & 4 & & 2 & 5 & & 4 & 4 & 34 & \\
\hline \multicolumn{2}{|c|}{ Profil ksvavwan } & \begin{tabular}{l|l}
4 & 1 \\
\end{tabular} & 4 & & 1 & 4 & 3 & & 4 & 34 & \\
\hline 1 & K001 & \begin{tabular}{l|l}
-1 & 1 \\
\end{tabular} & 1 & & c & 0 & & & 0 & $\begin{array}{ll}0 & 1\end{array}$ & \\
\hline $2^{2}$ & K002 & \begin{tabular}{l|l}
0 & 0
\end{tabular} & 0 & & 1 & 1 & & 2 & 0 & $\begin{array}{ll} & -1 \\
\end{array}$ & \\
\hline & eterangan & $n_{1}^{1}$ & 10 & & & 1 & $0-1$ & 1 & $0^{\circ}$ & & \\
\hline \multicolumn{12}{|c|}{ K01 = Kecerdasan } \\
\hline \multicolumn{12}{|c|}{ K02 = Sikap Kerja } \\
\hline \multicolumn{12}{|c|}{ K03 = Perilaku } \\
\hline \multicolumn{12}{|c|}{$\mathrm{K} 1=$ Sistematika berpikir } \\
\hline \multicolumn{12}{|c|}{ K2 = Logika Praktis } \\
\hline \multicolumn{12}{|c|}{$\mathrm{K} 3=$ Konsentrasi } \\
\hline \multicolumn{12}{|c|}{$\mathrm{K} 4=$ Antisipasi } \\
\hline \multicolumn{12}{|c|}{ SK1 = Ketelitian dan Tanggungjaawab } \\
\hline \multicolumn{12}{|c|}{ SK2 = Kehati-hatian } \\
\hline \multicolumn{12}{|c|}{ SK3 = Vitalitas dan Perencanaan } \\
\hline \multicolumn{12}{|c|}{ SK4 = Dorongan berprestasi } \\
\hline \multicolumn{12}{|c|}{ P1 = Kekuasaan } \\
\hline \multicolumn{12}{|c|}{$\mathrm{P} 2=$ Pengaruh } \\
\hline \multicolumn{12}{|c|}{ P3 = Keteguhan hati } \\
\hline \multicolumn{12}{|c|}{ P4 = Pemenuhan } \\
\hline & Pembol & obot: & & & & & & & & & \\
\hline
\end{tabular}

Tabel 7 :Pembobotan

\begin{tabular}{|c|c|c|c|c|c|c|c|c|c|c|c|c|c|}
\hline & & \multicolumn{5}{|c|}{ K.101 } & \multicolumn{3}{|c|}{ K402 } & \multicolumn{4}{|c|}{ KA0? } \\
\hline 4 & $\begin{array}{c}\text { IdKarvaw } \\
\text { an }\end{array}$ & $\begin{array}{l}\mathbf{K} \\
1\end{array}$ & $\begin{array}{l}\mathrm{K} \\
2\end{array}$ & 3 & & SK1 & $\begin{array}{c}\text { SK } \\
2\end{array}$ & SK3 & SK4 & $\begin{array}{l}P \\
1\end{array}$ & $\mathbf{P} 2$ & $\begin{array}{l}\mathrm{p} \\
3\end{array}$ & $\begin{array}{l}\mathbf{P} \\
4\end{array}$ \\
\hline 1 & Kona & 4 & 4. & 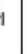 & z & , & 5 & 5 & 4 & , & , & 4 & 1 \\
\hline 2 & $\mathrm{~K} 002$ & 5 & 5 & 5 & 4.5 & 1.5 & 4 & 4,5 & 3 & 5 & 4. & 1 & 3 \\
\hline 3 & Kov3 & 3 & $\begin{array}{l}4, \\
5\end{array}$ & 5 & 4 & 4 & 4.4 & " & 4,5 & 5 & 5 & 5 & \\
\hline
\end{tabular}

e. Pengelompokkan Core Factor dan

Secondary Factor

Tabel 8 :Pengelompokkan Bobot Nilai

Gap Kecerdasan

\begin{tabular}{|l|l|l|l|l|l|l|l|}
\hline No & Id karvawan & K1 & K2 & K3 & K4 & $\begin{array}{l}\text { Core } \\
\text { Factor }\end{array}$ & $\begin{array}{l}\text { Secondary } \\
\text { Factor }\end{array}$ \\
\hline 1 & K001 & 4 & 4,5 & 4 & 3 & 4,25 & 3,5 \\
\hline 2 & K002 & 5 & 5 & 5 & 4,5 & 5 & 4,75 \\
\hline 3 & K003 & 3 & 4,5 & 5 & 4 & 3,75 & 4,5 \\
\hline
\end{tabular}

Tabel 9 :Pengelompokkan Bobot Nilai Gap Sikap Kerja

\begin{tabular}{|l|l|l|l|l|l|l|l|}
\hline No & Id karvawan & SK1 & SK2 & SK3 & SK4 & $\begin{array}{l}\text { Core } \\
\text { Factor }\end{array}$ & $\begin{array}{l}\text { Secondary } \\
\text { Factor }\end{array}$ \\
\hline 1 & K001 & 5 & 5 & 5 & 4 & 5 & 4,5 \\
\hline 2 & K002 & 4,5 & 4 & 4,5 & 3 & 4,25 & 3,75 \\
\hline 3 & K003 & 4 & 4 & 4,5 & 5 & 4 & 4,75 \\
\hline
\end{tabular}

Tabel 10 :Pengelompokkan Bobot Nilai Gap Perilaku

\begin{tabular}{|l|l|l|l|l|l|l|l|}
\hline No & Id karyawan & P1 & P2 & P3 & P4 & $\begin{array}{l}\text { Core } \\
\text { Factor }\end{array}$ & $\begin{array}{l}\text { Secondary } \\
\text { Factor }\end{array}$ \\
\hline 1 & K001 & 5 & 5 & 4 & 4 & 5 & 4 \\
\hline 2 & K002 & 5 & 4,5 & 4 & 3 & 4,75 & 3,5 \\
\hline 3 & K003 & 5 & 5 & 5 & 5 & 5 & 5 \\
\hline
\end{tabular}

f. Nilai Total Tiap Aspek

Tabel 11 : Nilai Total Tiap Aspek

\begin{tabular}{|l|l|l|l|l|}
\hline No & Id karyawan & Kecerdasan & $\begin{array}{l}\text { Sikap } \\
\text { kerja }\end{array}$ & Perilaku \\
\hline 1 & K001 & 3,8 & 4,7 & 4,4 \\
\hline 2 & K002 & 4,85 & 3,95 & 4 \\
\hline 3 & K003 & 4,2 & 4,4 & 5 \\
\hline
\end{tabular}

g. Perhitungan Ranking

Tabel 12 : Perhitungan Rangking

\begin{tabular}{|l|l|l|l|l|l|}
\hline No & Id karyawan & Kecerdasan & $\begin{array}{l}\text { Sikap } \\
\text { kerja }\end{array}$ & Perilaku & Hasil \\
\hline 1 & K001 & 1,14 & 1,645 & 1,54 & 4,325 \\
\hline 2 & K002 & 1,455 & 1,38 & 1,4 & 4,235 \\
\hline 3 & K003 & 1,26 & 1,54 & 1,75 & 4,55 \\
\hline
\end{tabular}

- Tampilan Menu Utama

Tampilan default ini terdiri dari empat sub menu yaitu menu home,login admin, login karyawandan login 
Penelitian Bidang Komputer Sains dan Pendidikan Informatika V3.i2(136-146)

pimpinanmenu untuk lebih jelasnya dapat dilihat pada Gambar2 berikut ini:

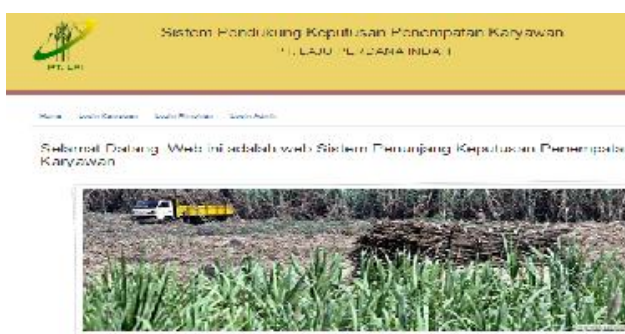

Gambar 1 :Tampilan Default

Sistem Pendukung Keputusan

Penempatan Karyawan

- Login

Formini digunakan untuk login user ke sistem. User yang menggunakan sistemakanlogin dengan user namedan password. Dalam login ini ada 3 user yaitu : admin,karyawan dan pimpinan. Untuk lebih jelasnya dapat dilihat pada Gambar 2 berikut ini:

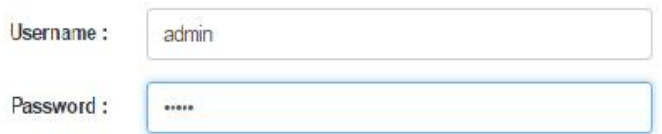

\section{$\operatorname{Login}$}

\section{Gambar 2 :FormLogin}

- Form Data Aspek dan Kriteria Form ini merupakan form pengaturan data aspek dan kriteria yang akan dinilai untuk penempatan karyawan. Untuk lebih jelasnya dapat dilihat pada gambar 3 berikut ini:
Aspek dan Kitteria

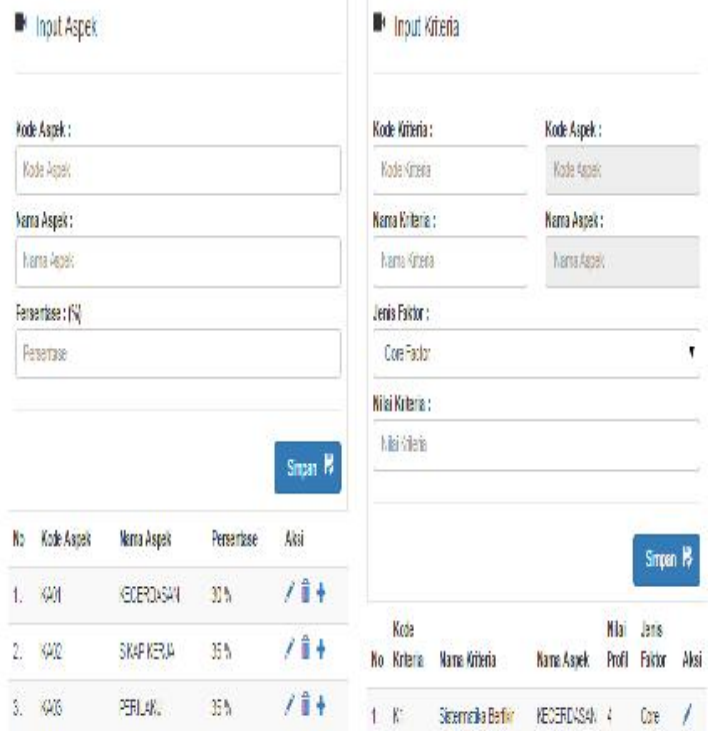

Gambar 3 :Form Pengaturan Data Aspek dan Kriteria

- Form Core dan Secondary Factor

Form ini berfungsi untuk menentukan nilai core dan secondary factor yang akan dinilai dalam penempatan karyawan. Untuk lebih jelasnya dapat dilihat pada Gambar 5 berikut ini:

CF dan SF

-

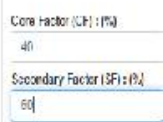

List Data $C=$ dan SF

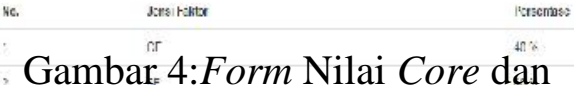

Secondary factor

\section{- Form Input Data Karyawan}

Form ini merupakan form untuk menginputkan data-data Karyawan. Lebih jelasnya dapat dilihat pada gambar 5 berikut ini: 
Penelitian Bidang Komputer Sains dan Pendidikan Informatika V3.i2(136-146)

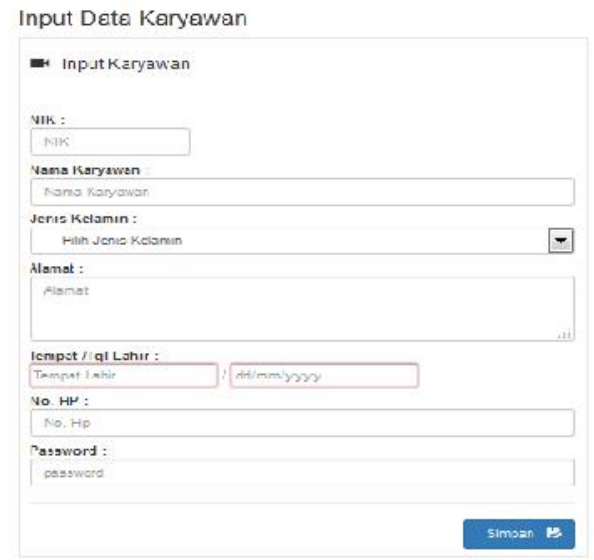

Gambar5 :Form Input Data

Karyawan

\section{- FormPenilaian}

Form ini merupakan form untuk menginputkan data-data nilai karyawan. Untuk lebih jelasnya dapat dilihat pada Gambar 6 berikut ini:

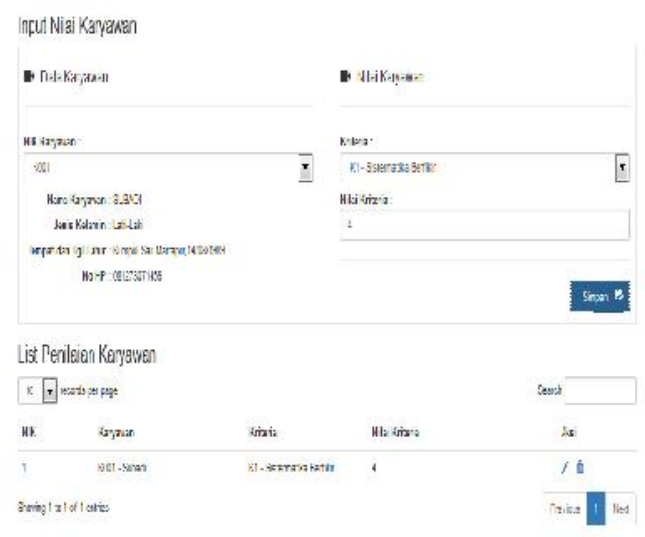

Gambar 6 :Form Penilaian Karyawan

- Report

Pada sub menu report terdapat form hasil akhir serta laporan yang dihasilkan dalam proses penempatan karyawan.

1) Form Hasil Akhir

Form ini Merupakan bagian output dalam sistem pendukung keputusan penempatan karyawan. Lebih jelasnya dapat dilihat pada Gambar 7 berikut ini:

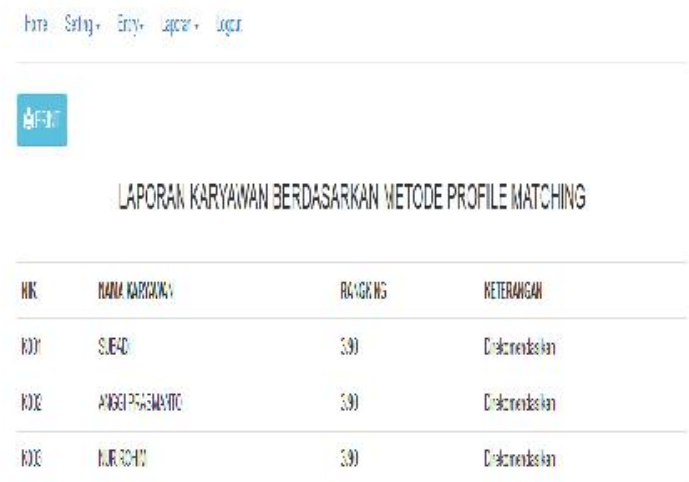

Gambar 7 :Form Hasil Akhir

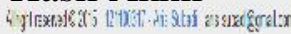

2) Laporan Data Perkaryawan

Laporan ini adalah hasil dari proses metode profile matching, Untuk lebih jelasnya dapat dilihat pada Gambar 8 berikut ini:

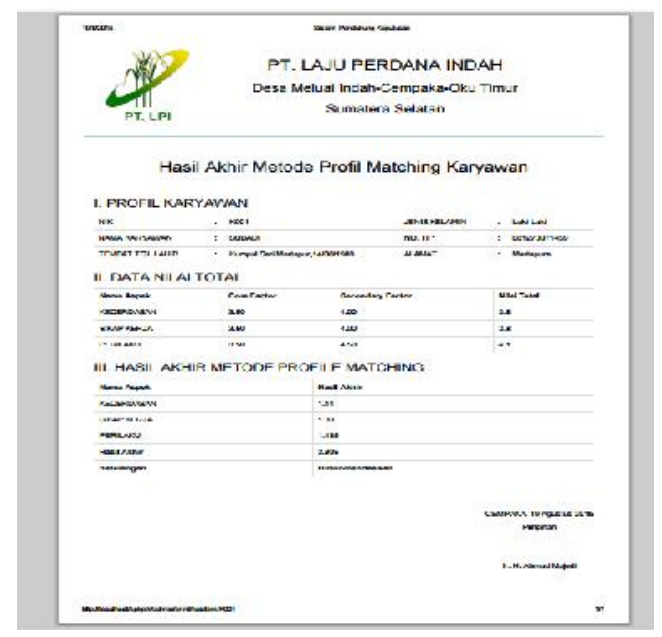

Gambar8 : Laporan Data Perkaryawan

3) Laporan Daftar Karyawan

Merupakan laporan daftar hasilseleksi karyawan berdasarkan nilai tertinggi. Untuk lebih jelasnya dapat dilihat pada 
Gambar 9 berikut ini:

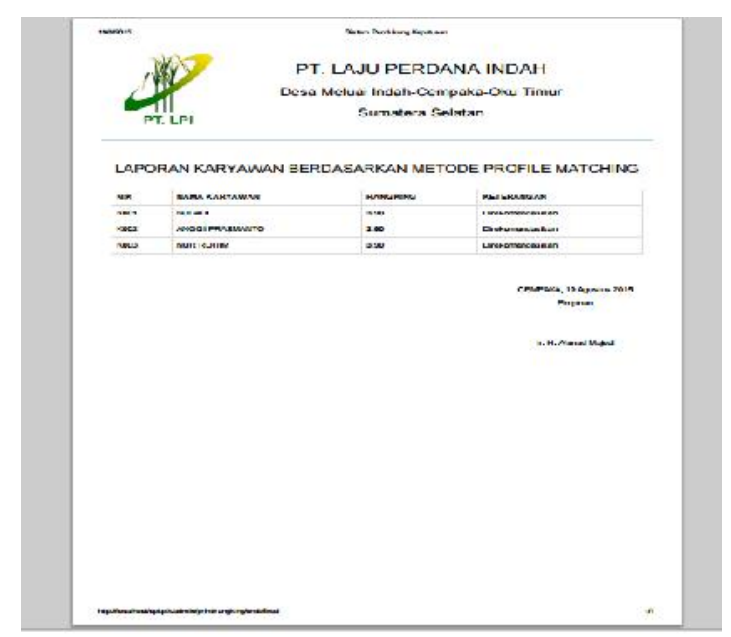

Gambar 9 : Laporan Daftar

Karyawan

\section{KESIMPULAN DAN SARAN}

Sistem Pendukung Keputusan ini menampilkan rangking dari karyawan sebagai bahan pertimbangan dan alat bantu dalam pengambilan keputusan untuk penempatan karyawan. Dengan menerapkan aplikasi sistem pendukung keputusan menggunakan metode profilematching untuk memudahkan peran pengambil keputusan dalam penempatan karyawan serta dapat memilih karyawan dengan cara yang lebih efektif dan efisien. Sistem ini hanya menjadi alat bantu bagi pengambil keputusan, keputusan akhir tetap berada ditangan pengambil keputusan.

Dalam penerapan sistem penunjang keputusan penempatan karyawan, sistem lama sebaiknya tetap berjalan seperti biasa hingga sistem pendukung keputusan yang baru tersebut siap untuk menggantikan sistem yang lama.Hendaknya ada suatu pelatihan atau training yang dilakukan kepada staf administrasi tentang penggunaan sistem penunjang keputusan penempatan karyawan pada PT. Laju Perdana Indah, sehingga sesuai dengan hasil yang diharapkan.

\section{UCAPAN TERIMAKASIH}

Ucapan terima kasih kepada STMIK Indonesia Padang yang telah membiayai penelitian ini dengan nomor kontrak 895.016/A.12/STMIK-I/2016.

\section{REFERENSI}

Ananta, P.W. \& Winiarti, S., 2013. MENGGUNAKAN METODE GAP KOMPETENSI. , 1, pp.574-583.

Ariantono, P.., Sudarma, M. \& Mertasana, A., 2015. Rancang Bangun Sistem Pendukung Keputusan Penentuan Kenaikan Posisi Jabatan Pada Instansi Pemerintahan Dengan Metode Profile Matching. , 2(2), pp.38-43.

Firdaus, M.A. \& Bardadi, A., 2010. Analisis Sistem Informasi Manajemen Perkuliahan pada Fakultas Ilmu Komputer Universitas Sriwijaya., 2(2), pp.272-285.

Handojo, A. et al., 2003. PEMBUATAN APLIKASI SISTEM PENDUKUNG KEPUTUSAN UNTUK PROSES KENAIKAN JABATAN DAN PERENCANAAN KARIR PADA PT . X Rachma Yunita. , 4(2), pp.98106.

Kasus, S. et al., 2013. Sistem Pendukung Keputusan Kenaikan Jabatan Menggunakan Metode Profile Matching. , pp.48-55. 
Penelitian Bidang Komputer Sains dan Pendidikan Informatika V3.i2(136-146)

Kusrini, 2007. Konsep dan Aplikasi

Sistem Pendukung Keputusan,

Yogyakarta: Andi Offset.

Nanda, A. \& Yani, R., 2016. PENGARUH

PENEMPATAN KARYAWAN

TERHADAP MOTIVASI DAN

KINERJA ( Studi pada karyawan PT

Perkebunan Nusantara $X(P G$

Watoetoelis ) Sidoarjo ),

Nuraini, C., Utama, D.N. \& Bey, Z., 2011. Implementasi Analisis Gap untuk

Sistem Pendukung Keputusan

( SPK ) Kenaikan Jabatan. , 4(1), pp.1-17.

Putri, N.E. \& Saleh, T., 2016. SISTEM

PENDUKUNG KEPUTUSAN

PEMILIHAN MAHASISWA

BERPRESTASI MENGGUNAKAN

METODE PROFILE MATCHING

PADA STMIK INDONESIA

PADANG. , 9(1), pp.13-29.

Setiawati, I., Abdillah, G. \& Hadiana, A.,

2016. SISTEM PENDUKUNG

KEPUTUSAN PENEMPATAN

KARYAWAN BERDASARKAN

TEST DOMINANT-INFLUENCE-

STEADY-COMPLIANCE (DISC)

MENGGUNAKAN METODE

PROFILE MATCHING. , pp.25-30. 